\title{
Discussion on Joint Council Management Mode of Archives and Library
}

\author{
Min Fu \\ Library, Jiangsu Institute of Commerce, Nanjing, 211168, China
}

\author{
Keyword: Council. Management. Library. Archives
}

\begin{abstract}
In the report of $18^{\text {th }}$ Third Plenary Session of Central Committee of the Party, the proposal of joint council for public libraries, museums, cultural centers and science museums, etc., has been put forward. Based on the management and cooperation actuality of archives and libraries, this paper has analyzed the essence, characteristics and implementation approaches of the joint council management mode of archives and libraries, and has provided the reference for reform of public benefit institutions.
\end{abstract}

\section{Background for Establishing Joint Council of Archives and Libraries}

In the report of $18^{\text {th }}$ Third Plenary Session of Central Committee of the Party, it has pointed out: "Explicit the function location of different cultural and public institutions; construct the corporate governance structure and perfect the performance evaluation mechanism. Promote the construction of joint council management for public libraries, museums, cultural centers and science museums, and attract relevant representatives, professionals and citizens participating in the management.” It is an important measurement to improve the mechanism innovation and the must to deepen the reform of our cultural and public institutions.

Municipal Party committee and government have issued the measurement: Seven Specific Reform Proposal for Innovation and Reform of Public Institution Mechanism (2007), therein the regulation: Suggestion on Construction and Perfection Implementation of Corporate Governance Structure of Public Institutions. The regulation has pointed out to implement mechanism of council among public institutions including libraries. The project of sharing national culture and information resources, launched by Ministry of Culture and Ministry of Finance in 2002, has integrated the cultural information resources of libraries, archives and museums and realized the share of cultural information among the nation. Additionally, many regional projects have promoted the integration and processing of cultural information resources to provide services to publics via Internet, through the cooperation with local libraries, archives and museums.

With the increase of national economy and the fast accumulation of material wealth over the society, public requires higher level of cultural consumption. Archives and libraries, as the cultural institutions providing the cultural information resources to public, are required to provide the public with fruitful resources and the fast accesses to reach these resources. At this stage, the best approach for archives and libraries is to cooperate together deeply and broadly, so that they can have better integration on cultural resources and provide optimized services. However, the supervised department of archives is National Archive Bureau, while that of libraries is Ministry of Culture. The two departments are belonging to different administrations respectively and between the upper administrations, there is lack of scientific and rational cooperation mechanism. Even via the existing technical approach to share the resources, contribution of digital platform, the problems have been found for period, such as redundant resource construction and different functions of resources carriers. Therefore, it is necessary to establish a joint management organization of archives and libraries, which can project the development globally and manage archives and libraries holistically. It will promote the cooperation of archives and libraries, while make efficient use of personnel and expense to obtain more effective results. Under contemporary situation, it is the requirements to bring in council management of archives and libraries to cope with the public institution reform, to follow up the transform of government functions, and to establish and perfect the corporate governance 
structure for public benefit cultural public institutions. It should become the inevitable choice of the management mechanism reform for public institutions to bring in the mechanism of council.

\section{The Essence and Characteristics of Joint Council Management Mode}

Joint council management mode means the joint council is a corporate governance structure established by both archives and libraries, to manage and supervise individuals. The corporate governance structure of the joint council consists of six components: the first one is the Council, which is the dominant capability organism and final decision maker of all the individuals. The second one is the Curator Executive Committee, which is the manager of the alliance and executes the important decisions in alliance development and activities. The third one is the Consultation Committee, which offers consultation services for the alliance to deal with the problems that may occur during the development and operation of the council. The forth one is Resources Construction Committee, which determines the development direction of the resources holding by alliance, so that the alliance can provide better and more effective resources to the public. The fifth one is the Public Service Committee, which is the bridge between public and alliance for the better communication of information. The last one is the Supervision Committee, which is the supervisor of the alliance, and in supervision of the activities of alliance. The corporate governance structure schematic diagram is shown in Figure 1:

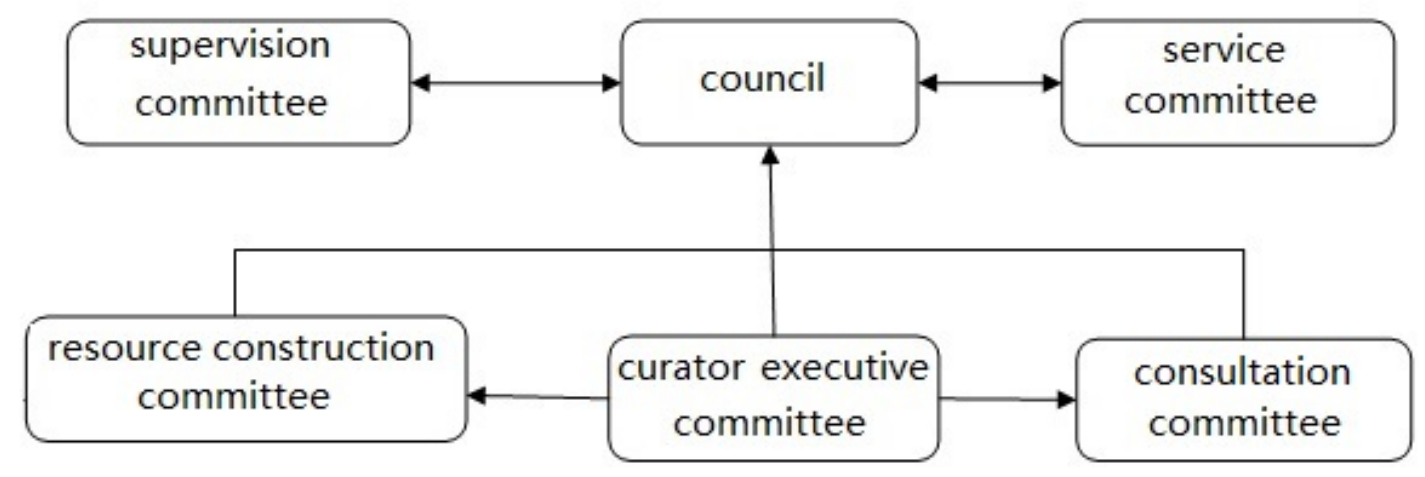

Fig.1

The joint council management mode is the corporate governance structure in reform of public cultural institutions, which is different from the board of directors in corporate governance structure of an enterprise. All the properties of the joint council are national assets and the property right is turned over to the state. For the enterprises, their board of directors in corporate governance structure is elected via general meeting of stockholders, to protect the rights and interests of sponsors; while this kind of election is not suitable for the joint council. The council must responsible to the assets as the owner of national assets, and generate based on the government administrative department, which is the rational approach. At the first place, this mode has clarified property relations, making the joint council become the investment subject with the authority of government. The ownership and managerial authority are separated in this management system and organization, which has effectively promoted the construction of system of modern public cultural institution, and has promoted the effective allocation of resources. Secondly, this mode copes with the environment of market economy, forming an effective management mode in team, which has shown the scientific and effective management. Finally, this mode has enhanced the function of democratic management, which has broadened the communication path for the public, so that public will participate in the management actively, to further improve the efficiency of management. 


\section{Discussion the Management Mode of Joint Council}

\section{Making Decisions}

\section{Scale and Member Composition of Joint Council}

There are two regulations, the Regulation on Foundation Administration (Decree of the State Council, No. 400) in 2004 and the Interim Regulations on Registration and Management for Private Non-Enterprise Organization (Decree of the State Council, No. 251), which have determined the basic framework of internal governance for Chinese non-profit organizations. The model text in constitution has restricted the total number of members in the council for no more than 25 . This number has offered the standard for the joint council of archives and libraries. The member of the joint council should be the representatives from relevant government supervision department, archives and libraries, the service objects and other relevant area. The other relevant representatives mean the professionals and celebrities in the area of archives and library management, who can offer their suggestions and advices to improve the development of public culture service.

\section{Responsibility of Joint Council}

The council is the decision maker of alliance, holding the rights of making decisions for the alliance. All activities of the council is under democracy, justice and publicity. In order to maintain the publicity and transparency, at the beginning of the council, the acknowledged constitution, sound and integrated regulations and names and content for the regulations must be discussed via board meeting. The responsibilities of the council are mainly the following: discover the innovation approaches actively and determine the development direction of alliance; decide the development strategy of alliance and perform the significant right of decision making; consider and approve the annual working plan of the alliance and individuals; review the situation of plan execution and the development planning of the alliance and individuals; deliberate the annual report and financial revenues of alliance; Determine the indications of performance evaluation and the criteria of services of individuals in the alliance; Determine the work performance and efficiency of curators of individuals in the alliance.

\section{Execution of Curator Executive Committee}

\section{Member Composition of Curator Executive Committee}

The curator executive committee is the executive layer of the alliance, to execute the decisions of the alliance and manage the routine work of individuals. The member of curator executive committee should consist of the curators and vice curators of the archives and libraries in the alliance.

\section{Responsibility of Curator Executive Committee}

The responsibility of Curator Executive Committee is as following: take charge of management of individuals; understand and perform the decision goal and tasks of the council; organize and implement the resolutions of the council; execute the relevant policies of the council; Report the work results to the council periodically, make and implement the detailed working plans, approaches and conditions of each decision; protocol the organization setting proposal and management regulation of individuals; submit the appointment for curators and relevant department heads to council; determine the responsibilities of individuals and the occupations of individuals; allocate, employ and train the relevant personnel rationally to improve the entire quality of the team.

\section{Consulting Service of Consultation Committee}

\section{Member Composition of Consultation Committee}

Consultation Committee will offer consultation service to the development of alliance and individuals. The service covers several aspects including service way of alliance, academic research and technology, while its member must choose from the head of technical department of individuals, the head from reader service department, other advanced staff in the individuals, and relevant professionals and celebrities.

\section{Responsibility of Consultation Committee}

In general, the responsibility of consultation committee is to provide the consultation service for the alliance including service content and technology. In detail, the service covers following aspects: analyze the method of service, location and the range of service and determine the long-term planning 
for the alliance; the committee must provide the overall planning for individual branches in the alliance together with their staff, including the evaluation of the function in the alliance of each branch, and proportion analysis of each kind of branch in the alliance; the committee must make full use of the modern information technology to help the alliance in developing powerful technical infrastructure and constructing the public-oriented digital platform; With the professions and expertise from experts, maintain the existing technical resources and promote the technical innovation of public digital service; Enhance the cooperation and coordination of individuals and improve the construction and share of resources.

\section{Resource Construction Committee}

\section{Member Composition of Resource Construction Committee}

The main responsibility of resource construction committee is to make overall and integrated arrangement and long-term planning for the alliance and the holding and storage for each branch. Therefore, member of the committee must be chosen from the curators and vice curators, the heads of procurement department, heads of technical department or the technical key persons, holding managers, and relevant professors and celebrities.

\section{Responsibility of Resource Construction Committee}

The responsibilities of resource construction committee are the following: make and plan the development policies for alliance and the holding and storage in branches; provide the policy framework for the maintenance and development for the alliance and the holding of branches; make sure the consecutiveness and consistency of the holdings development of branches; take in charge of guiding and organizing the overall research of resources construction of alliance; make and revise the interview principles, plans, regulations and budgets; coordinate the relationship between branches and resources searching department, to supervise the relevant business, and to make sure the functions of resources construction system has been fully used; allocate the categories and quantities of holdings, to construct rational structural, outstanding focused alliance holding, and to construct characteristic and qualified holding structure; Make and perfect the measurements and methods for procurement, obtaining, protection and reservation of special resources; Discover the methods of holds in the alliance actively, promoting the alliance providing better service to the public, with the realization of public recreation, education and scientific research.

\section{Public Service Committee}

\section{Member Composition of Public Service Committee}

The intention of public service committee is to bridge the communication path between the alliance and public, to improve the communication of the two parties more frequently and more widely, so that improve the public cultural service efficiency. The member of the committee must be chosen from the public service subjects, heads of service department, the professionals and celebrities in archives, books and materials from the society.

\section{Responsibility of Public Service Committee}

The public service committee must listen to and participate in the discussion of development planning, working plans and significant decision proposals of alliance, and provide their opinions and suggestions; perform the advertisement and education activities among public in assisting alliance and popularizing the awareness of alliance; perform surveys among public periodically to understand the requirements for the public to cultural information resources; listen to the suggestions from professionals and celebrities about the development, decisions and activities of alliance, and collect and report the suggestions to council periodically.

\section{Supervision Committee}

\section{Member Composition of Supervision Committee}

The fundamental purpose of supervision committee is to provide effective supervision and restriction to the rights of decision layer and execution layer. The member of supervision committee should come from the relevant heads of government administrations, secretary of the party committee of archives and libraries, the ordinary staff in branches, and the service subjects who have the knowledge of finance, accounting and law. 


\section{Responsibility of Supervision Committee}

The responsibilities of supervision committee are the following: communicate with publics to understand their requirements; follow up the developing trend of public cultural service; participate in the work of other committees actively; grasp the regulatory and policy planning related to archives and libraries, supervising to make sure all the activities of council are performed with in the permitted range of regulations and policies; review strictly on the making of financial policies, using and allocating the budgets.

\section{Conclusion}

It is the further integration of cultural resources and the innovation in management, for the construction of council of archives and libraries, with the joint council management mode. The construction of joint council has improved the resources integration from technology to management, which is the important measurement of archives and libraries from simple coordination to deep cooperation. This management mode is the beneficial attempting of the reform of public cultural institutions, which copes with the overall trend of the public institution reform.

\section{References}

[1]. Li Nong: the Cooperation Trend of European Libraries, Museums and Archives, Journal of Library, 2008(8)

[2]. Shenzhen.Municipal Party Committee General Office and Shenzhen People's Government General Office, Notification about Publishing the Seven Specific Reform Approaches for Reform Innovation of Public Institution (2010-06-07), http://www.law-lib.com/law/law_view.asp? Id=246627

[3]. Tian Kai: Development and Operation of Chinese Non-benefit Organization Council Mechanism, Comparison of Economics and Society Mechanism, 2009(2).

[4]. Feng Jia: Foreign Public Libraries Council Mechanism and Enlightenment- Case Study on Public Library Council Mechanism in Boston of U.S.A,, Construction of Libraries, 2010(6).

[5]. Jack: Council of British Museums, Archives and Libraries, Chinese Archive, 2004(2) 